аспирант социологического факультета Московского государственного университета имени М.В. Ломоносова

\section{СОВРЕМЕННАЯ СОЦИАЛЬНАЯ ПОЛИТИКА В РОССИИ: АКТУАЛЬНЫЕ ПРОБЛЕМЫ И ВОЗМОЖНЫЕ ПУТИ РЕШЕНИЯ}

\section{Аннотация}

В статье исследуются вопросы реализации социальной политики России в условиях современности. Сформулированы основные проблемы ее проведения. Социальная политика - важная часть стратегии государства, относящейся к социальной сфере. В различных документах представлено множество определений социальной политики, однако в узком понимании это поддержка слабых, незащищенных слоев населения. Сделан акцент на том, что социальная политика отражает интересы современного общества и является важной частью деятельности современного государства. Обозначены основные сферы социальной политики, выделены ее основные направления. Формулируются ключевые проблемы доступности жилья, образования, здравоохранения в России. Проведен анализ благосостояния и уровня жизни населения России. Проанализированы меры государственной политики по исправлению сложившейся ситуации. Описаны модели социальной политики, разработанные автором, выявлены их положительные и отрицательные черты.

Ключевые слова:

социальная политика в России, образование, здравоохранение, благосостояние населения, уровень жизни, модели социальной политики, принципы социальной политики, доступность жилья, качественная медицинская помощь. \\ PhD student, \\ Sociology Department, \\ Lomonosov Moscow State University \\ MODERN SOCIAL \\ POLICY IN RUSSIA: \\ TOPICAL ISSUES \\ AND POSSIBLE SOLUTIONS
}

Summary:

The research discusses the implementation of social policy in Russia in the modern context. The main problems of its implementation are defined. Social policy is an important part of the state strategy related to the social sphere. There are many definitions of social policy in various documents; however, in a narrow sense, it is the support for vulnerable, underprivileged people. The author emphasizes that social policy reflects the interests of modern society and is a pivotal part of the modern state activities. The scope and focus area of social policy are determined. The research defines the key issues of housing affordability, access to education and healthcare in Russia. The well-being and living standards of Russian people are analyzed. Public policy measures to remedy the situation are discussed. The author presents the models of social policy and reveals its positive and negative aspects.

Keywords: social policy in Russia, education, healthcare, well-being of the population, living standards, models of social policy, principles of social policy, housing affordability, quality medical care.

Согласно ст. 7 Конституции РФ, «Российская Федерация - социальное государство, политика которого направлена на создание условий, обеспечивающих достойную жизнь и свободное развитие человека» [1]. Социальная политика возникла в XIX в. как практика германского государства по созданию условий жизнедеятельности социальных групп, классов и индивидов, с течением времени и в результате усложнения задач стала требовать серьезного теоретического осмысления как миротворящая политика [2, с. 76]. Сущность социальной политики заключается в деятельности государства и других институтов по развитию и совершенствованию социальной сферы, настройке социального механизма государственного управления.

Нами разработаны различные социальные модели.

Патерналистская модель - покровительство государства над обществом. Впервые данная модель была предложена Я. Корнаи и характерна для стран Запада [3]. Патерналистско-административная модель долгое время существовала в СССР. Данная модель включает ответственность государства за социально-экономическое положение граждан. К положительным чертам данной модели можно отнести:

- огосударствление социальной сферы, ее отдельных отраслей и учреждений;

- равенство материальных благ и услуг;

- гарантированную всеобщую занятость, отсутствие безработицы;

- отсутствие рыночных отношений в отраслях социальной сферы.

Применение патерналистской модели социальной политики в СССР было во многом предопределено исторически, соответствовало особенностям менталитета, сформировавшегося в Российской империи, и в течение нескольких десятилетий давало положительные результаты в 
различных областях социальной сфреры. Однако на определенном этапе развития общества в условиях научно-технической революции патерналистская модель стала существенным тормозом для совершенствования социально-экономических отношений. Мы считаем, что данная модель даст чувство социальной защищенности гражданам, социальную стабильность.

Либеральная модель - ответственность каждого члена общества за свою судьбу и судьбу своей семьи. Отрицательный момент - существенные различия между уровнями потребления экономически сильных и экономически слабых граждан. Положительный - финансирование социальных программ в первую очередь за счет частных сбережений и частного страхования. При этом задачей государства является стимулирование роста личных доходов граждан. Как и две другие модели - корпоративная и социал-демократическая, либеральная нигде не встречается в чистом виде. Эта модель эффективна лишь в условиях экономической стабильности или подъема, но при спаде и вынужденном сокращении производства, сокращении социальных программ в тяжелом положении оказываются многие социальные группы: женщины, молодежь, пожилые люди.

Либеральная модель обладает такой негативной чертой, как дифференциация населения по уровню доходов. Бедные слои населения, чьи доходы ниже величины прожиточного минимума, могут довольствоваться минимальным уровнем социальных услуг. Положительные черты - диффреренциация услуг в зависимости от доходов, низкий уровень налогообложения граждан.

Социал-демократическая модель - социальное обеспечение - это право всех граждан, гарантированное в основном государственным сектором. Для того чтобы эта модель начала работать в России, нужно добиться того, чтобы социальные услуги предоставлялись всем гражданам, а не тем, кто в них нуждается. Данная модель направлена на становление стабильного среднего класса.

Консервативная модель - основное внимание уделяется занятости, а не социальному перераспределению. Консервативная модель существует в Австрии, Германии, Италии и Франции. Труд определяет последующее социальное обеспечение. Для хорошо организованных рабочих в процветающих отраслях результат может быть очень высок. Другие вынуждены рассчитывать на местные благотворительные органы и общественную помощь, обычно не очень большую.

В данном случае мы видим феномен работающего бедняка: множество людей работают, но заработная плата, которую им выплачивают, не позволяет избавится от бедности, или же они заняты крайне непостоянно - сезонные работы, неполный рабочий день. И.А. Черногор предложила такой термин, как «работающие нищие». Данный феномен характерен не только для России, но и для многих постсоветских республик: Киргизии, Казахстана, Таджикистана и др. Граждане, работая, не могут обеспечить себя и свою семью достойным уровнем жизни и находятся за гранью [4].

Проблемы, с которыми сталкиваются различные институциональные структуры социальной политики, можно свести к следующим.

Во-первых, высокая диффреренциация доходов. Большая часть населения страны находится за чертой бедности и нуждается в социальной защищенности со стороны государства. Социальная политика России должна быть кардинально изменена. В России в 2017 г. по данным выборочного обследования по уровню благосостояния 19,6 млн человек, или 13,4 \%, имели среднедушевой денежный доход ниже величины прожиточного минимума. В 2017 г. 12,7 \% населения страны находятся за чертой бедности [5]. Проблема бедности фрормирует серьезную угрозу социально-экономической безопасности и независимости и касается не отдельного человека, а общества в целом.

Таблица 1 - Численность населения России с денежными доходами ниже величины прожиточного минимума за 2012-2017 гг. [6]

\begin{tabular}{|l|l|c|c|c|c|c|c|}
\hline \multicolumn{2}{|c|}{ Показатель } & $\mathbf{2 0 1 2}$ & $\mathbf{2 0 1 3}$ & $\mathbf{2 0 1 4}$ & $\mathbf{2 0 1 5}$ & $\mathbf{2 0 1 6}$ & $\mathbf{2 0 1 7}$ \\
\hline $\begin{array}{l}\text { Численность населения России с } \\
\text { денежными доходами ниже вели- }\end{array}$ & $\begin{array}{l}\text { \%лн чел. } \\
\text { чины общей числен- } \\
\text { нрожиточного минимума }\end{array}$ & 15,4 & 15,5 & 16,1 & 19,5 & 19,6 & 18,9 \\
\hline
\end{tabular}

С 1 мая 2018 г. впервые за всю историю минимальный размер оплаты труда (далее МРОТ) и прожиточный минимум сравнялись. Это положительно скажется на доходах около 4 млн человек [7].

По данным Росстата уровень МРОТ в десять раз меньше, чем в более развитых европейских странах. В 2017 г. МРОТ составил 121,42 евро, в Германии эта сумма в 10 раз больше и составляет 1473 евро, а в Люксембурге - 1922,96 евро [8]. Сегодня Россия значительно отстает по уровню жизни от развитых стран. Население не может обеспечить себя даже минимальным набором продуктов питания, одежды, обуви. Большая часть населения страны находится на грани выживания. По нашему мнению, необходимо повышать размеры МРОТ до уровня развитых стран. Считаем необходимым ввести прогрессивную шкалу налога на доходы физических лиц (далее - НДФЛ). Для этого следует граждан, размер заработной платы которых равен МРОТ, 
освободить от уплаты НДФЛ (сейчас ставка НДФЛ составляет 13 \%). На самом деле предложения по введению прогрессивной системы налогообложения в Госдуму поступают ежегодно. Основная причина, по которой данного изменения не происходит, - отток высококвалифицированных кадров из страны, снижение инвестиционной привлекательности России. Но считаем, что это вопрос времени, и в недалеком будущем прогрессивную шкалу налогообложения НДФЛ все-таки введут.

Во-вторых, это ситуация с ЖКХ. Именно эту проблему можно назвать основной. Необходимость обеспечения качественными услугами ЖКХ граждан России описана в госпрограмме «Обеспечение доступным и комфортным жильем и коммунальными услугами граждан Российской Федерации» [9]. Общие объемы фринансирования ее мероприятий: в 2015 г. - 96 млрд р.; 2016 - 50,7 (почти в два раза меньше); 2017 - 54,9; 2018 - 47,2; 2019 - 49,3; в 2020 г. 51,4 млрд р. По данным Росстата этот процент составляет $11 \%$ на каждого члена семьи, но если, например, это семья из трех человек, а женщина находится в отпуске по уходу за ребенком, этот процент в структуре доходов семьи составит 30 \% (таблица 2).

Таблица 2 - Состав потребительских расходов ЖКХ на человека за 2011-2016 гг. [10]

\begin{tabular}{|l|l|c|c|c|c|c|c|}
\hline \multicolumn{2}{|c|}{ Показатель } & $\mathbf{2 0 1 1}$ & $\mathbf{2 0 1 2}$ & $\mathbf{2 0 1 3}$ & $\mathbf{2 0 1 4}$ & $\mathbf{2 0 1 5}$ & $\mathbf{2 0 1 6}$ \\
\hline \multirow{2}{*}{ Сумма } & р. & 1281,8 & 1372,1 & 1435,1 & 1511,6 & 1589,6 & 1815,9 \\
\cline { 2 - 8 } & \% от общего дохода & 11,4 & 10,9 & 10,5 & 10,3 & 10,8 & 11,3 \\
\hline
\end{tabular}

В-третьих, это безработица. Официально по данным Росстата уровень безработицы составляет 5,5\%, снижение по аналогии с предыдущим периодом составило 0,1\%. Эта информация не совсем объективна, так как это только те граждане, которые были зарегистрированы в качестве безработных в центрах занятости (таблица 3).

Таблица 3 - Зарегистрированная безработица в России по данным Росстата 3а 2011-2016 гr., \%

\begin{tabular}{|c|c|c|c|c|c|c|}
\hline Показатель & $\mathbf{2 0 1 1}$ & $\mathbf{2 0 1 2}$ & $\mathbf{2 0 1 3}$ & $\mathbf{2 0 1 4}$ & $\mathbf{2 0 1 5}$ & $\mathbf{2 0 1 6}$ \\
\hline Безработица & 6,5 & 5,5 & 5,5 & 5,2 & 5,6 & 5,5 \\
\hline
\end{tabular}

Средний возраст безработных составляет 40,7 года (рисунок 1). В 2016 г. 51,1 \% всех безработных находятся в возрасте от 30 до 49 лет [11].

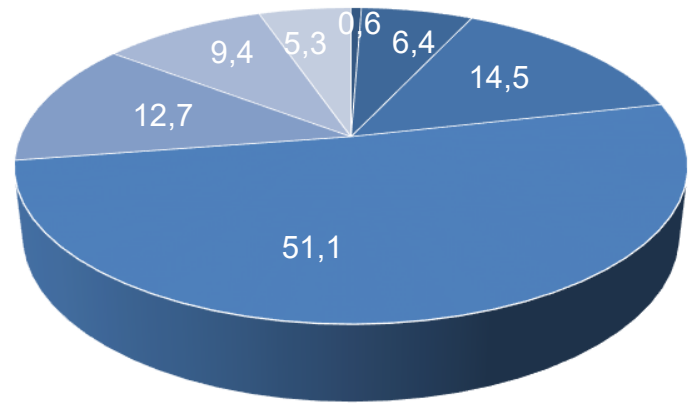

$$
\begin{aligned}
& \text { - 0-18 лет } \\
& \text { - 19-24 года } \\
& \text { - 25-29 лет } \\
& \text { - 30-49 лет } \\
& \text { - 50-54 года } \\
& \text { - 55-59 лет } \\
& \text { = 60-72 года }
\end{aligned}
$$

\section{Рисунок 1 - Структура безработных по возрасту в 2016 г., \%}

Помимо безработицы существует проблема низкого уровня занятости населения. Для того чтобы снизить процент безработицы, считаем необходимым осуществлять трудоустройство выпускников после окончания вузов. На данный момент проблемы трудоустройства выпускников вузов становятся особенно актуальными [12]. Уже на 4-5-х курсах студенты задумываются о том, где им работать после окончания вуза. В советское время механизм трудоустройства выпускников был отлажен - они работали по распределению. В соответствии с Постановлением ЦИК и СНК СССР от 15 сентября 1933 г. «Об улучшении использования молодых специалистов», все оканчивающие вузы и техникумы были обязаны проработать в течение пяти лет на конкретных производствах в системе того наркомата, в ведении которого находилось учебное заведение [13]. Всякое самовольное устройство на работу после окончания учебного заведения или неприбытие к месту работы согласно выданному ведомством наряду рассматривалось как нарушение закона. Считаем необходимым ввести трудоустройство выпускников по распределению. Заключение контракта должно происходить на первом курсе института. Все желающие могут подписать контракт. Этим мы обеспечим трудоустройство молодежи. Молодые люди будут уверены в своем будущем и социально защищены.

Сейчас популярность приобрела самозанятость населения. Также фрилансеры, блогеры это совершенно новая категория самозанятых, которые на сегодняшний день нигде не учитываются, а они должны платить налоги и социальные взносы. Предлагаем законодательно закрепить 
данную категорию граждан. Налоги, которые они будут платить со своих доходов, следует направить на финансирование социальной политики государства.

Следующим шагом может выступать переобучение безработных, предоставление им возможности бесплатно получить другую квалификацию, которая сейчас популярна на рынке.

B-четвертых, это доступность жилья. Российская Федерация определила некоторую категорию граждан, которую государство должно обеспечить жильем. В эту категорию входят не только малоимущие, но и работники бюджетной сферы, молодые семьи и другие категории граждан. Опишем авторские варианты решения этой проблемы. Первым предложением станет снижение ставки по ипотеке не до 6 \%, а до 1 или $2 \%$, как это происходит в развивающихся странах. Предлагаем действовать по примеру тех стран, которые в этом преуспели, - Сингапура и Германии. Следующее предложение - массовое строительство социального жилья. Необходимо давать семьям возможность выкупать такие квартиры под государственное субсидирование такой покупки. Размер субсидии ограничить до суммы в 300000 р. Целесообразно установить ограничение: субсидию в 300000 р. выдавать гражданам как единовременную выплату на приобретение жилья в том случае, если непрерывный трудовой стаж гражданина составляет десять лет и более. Тем самым будет обеспечено снижение доли безработных. После получения субсидии семья может купить квартиру в социальных домах под низкий процент по ипотеке. Третье предложение - это программа «Социальное жилье» для всех граждан. Есть необходимость строительства социальных домов, в которых будет выполнен косметический ремонт. Возможность получить такую субсидию можно описать в программе. Например, необходимо внести взнос в сумме 700000 р. Затем, собрав полный пакет документов, семья может получить социальное жилье. Жилье может быть государственным, а не частным. Для реализации предложенных вариантов необходимо реформировать сферу жилищного строительства, ввести программу «Социальное жилье».

В-пятых, это проблемы в сфере пенсионного обеспечения граждан. Конечно, низкий уровень пенсий остается важной проблемой социальной обеспеченности граждан. Низкий уровень жизни пенсионера - это социальная проблема. Большинству пенсионеров приходится продолжать работать, вместо того чтобы уйти на заслуженный отдых. Постоянно обсуждается вопрос о повышении пенсионного возраста россиян. Мы выступаем против этого, так как считаем, что пенсионерам нужно обеспечить достойный уровень пенсии, как в странах Запада. Нами был произведен анализ пенсий в Германии и России. Средняя продолжительность жизни в России в 2016 г. - 66 лет, это самый низкий показатель (таблица 4). Согласно прогнозам ООН, количество жителей планеты в возрасте 80 лет и старше увеличится с 137 млн в 2017 г. до 425 млн в 2050 г. К 2100 г. эта цифра составит 909 млн, что почти в семь раз больше показателя 2017 г. В Германии, по данным ООН, самое лучшее пенсионное обеспечение в мире [14]. В Германии у пожилых людей существуют два источника доходов: государственное пенсионное обеспечение и частные фонды. В Германии если гражданин проработал 5 лет и менее, ему платить пенсию не будут. Пенсионный возраст в Германии составляет 67 лет (выше, чем в России), а продолжительность жизни выше, чем у россиян, и составляет 79 лет (в России - 66 лет). По нашему мнению, такая продолжительность жизни может быть обеспечена за счет социальной политики, проводимой государством (таблица 4).

Таблица 4 - Средний размер пенсии и средняя продолжительность жизни по некоторым странам в 2016 г. [15]

\begin{tabular}{|l|c|c|c|c|c|}
\hline \multirow{2}{*}{ Страна } & Пенсионный возраст & $\begin{array}{c}\text { Средняя } \\
\text { продолжительность } \\
\text { жужчин }\end{array}$ & $\begin{array}{c}\text { Средний } \\
\text { жазмер пенсии, } \\
\text { долл. в месяц }\end{array}$ & $\begin{array}{c}\text { Средний размер пенсии } \\
\text { в странах в сравнении } \\
\text { с Россией, раз }\end{array}$ \\
\hline Япония & 70 & 70 & 82,1 & 717 & 2,5 \\
\hline Дания & 67 & 67 & 78,3 & 2800 & 9,8 \\
\hline Норвегия & 67 & 67 & 79,9 & 1542 & 5,4 \\
\hline США & 65 & 65 & 78,1 & 1164 & 4 \\
\hline Канада & 65 & 65 & 81,2 & 667 & 3 \\
\hline Швеция & 65 & 64 & 80,9 & 833 & 4,2 \\
\hline Германия & 67 & 67 & 79,3 & 1200 & - \\
\hline Россия & $\mathbf{6 0}$ & $\mathbf{5 5}$ & $\mathbf{6 6}$ & $\mathbf{2 8 5}$ & \\
\hline
\end{tabular}

Средний размер пенсии в Дании больше, чем в России, в 9,8 раза, в Японии - 2,5, Норвегии - 5,4, США - 4, Швеции - 3, Канаде - 2,3, в Германии - в 4 раза. Пенсионный возраст в этих странах не влияет на данные выплаты [16].

В-шестых, это доступность здравоохранения. Проблемы, существующие в здравоохранении, - это недостаточная эффективность финансирования здравоохранения и нехватка высококвалифицированных кадров. Необходимо укрепить защиту прав населения на получение качественной медицинской помощи, главная цель которого - обеспечить качественную медицинскую 
помощь. Для этого считаем необходимым ввести рейтинговую оценку деятельности больницы, врача, медсестры, дать возможность пациентам оценивать деятельность врачей, медицинских сестер, от этой оценки будет зависеть их заработная плата. Рейтинговая оценка поможет решить две проблемы: предоставление качественных услуг и оплата труда медицинских работников. При обращении в медицинские учреждения мы часто сталкиваемся с тем, что сотрудники не заинтересованы в проблемах пациента. Это в корне изменится, если будет введена рейтинговая оценка деятельности медицинского персонала. Предлагаем провести рефинансирование системы здравоохранения путем введения рейтинговой системы оплаты труда медицинских работников. Введение рейтинговой оценки медицинских услуг необходимо мотивировать тем, что будет улучшаться качество медицинских услуг [17]. Нужно продолжить научные исследования для улучшения качества медицинских услуг и лекарств. Должна соблюдаться «триада А. Донатабедиана»: структура (условия медицинской помощи) - процесс (вид помощи) - результат (состояние пациента после получение медицинской помощи) [18]. Поэтому важнейшим интегральным субъективным показателем качества оказанной помощи является удовлетворенность пациента (в иностранной литературе наряду с ним используется показатель «понимание нужд потребителя»). Его детерминантами служат удовлетворенность пациента своим здоровьем после лечения, удовлетворенность состоянием здоровья пациента его родственников, удовлетворенность качеством оказанной медицинской помощи, удовлетворенность бытовыми условиями и уходом.

В-седьмых, это доступность образования. Существует ряд проблем и несовершенств в образовании в России. Первое - это школьное образование. На наш взгляд, необходимо ввести профильное обучение. С момента школьного образования школьник будет знать, кем он станет в будущем, в какой вуз поступит и как сможет достичь определенной цели, поставленной перед ним еще в школе. Этот пример профильного образования используется в различных странах. Организация профильной подготовки различается по способу формирования индивидуального учебного плана учащегося: от достаточно жестко фриксированного перечня обязательных учебных курсов (Франция, Германия) до возможности набора из множества курсов, предлагаемых за весь период обучения (Англия, Шотландия, США и др.). Как правило, школьники должны выбрать не менее 15 и не более 25 учебных курсов продолжительностью до одного семестра. Аналогами таких курсов в России можно считать учебные модули, из которых возможно строить множество самостоятельных курсов [19]. Профильная школа выделяется как самостоятельный вид образовательного учреждения: лицей - во Франции, гимназия - в Германии, высшая школа - в США. Окончание профильной школы и сдача итоговых тестов дают возможность поступать в университеты. Интегрированность России в международное сообщество определяет необходимость изучения зарубежного опыта развития профильного образования. Необходимо ввести его и в России. К сожалению, у нас в стране профильного образования нет. В конце обучения школьники сдают ЕГЭ. Школьники сами выбирают дисциплины, которые они будут сдавать. Чаще всего, для того чтобы сдать ЕГЭ, родителям приходится прибегать к услугам репетиторов. Родители тратят деньги на репетиторов, тогда как подготовка детей по профильному образованию помогла бы избавить семью от подобного рода трат. Качество среднего и высшего образования в России снижается. Для повышения качества высшего образования предлагаем развивать дистанционное обучение, которому уже сейчас уделяется огромное внимание.

Таким образом, преобразования в социальной сфере должны быть направлены на достижение определенных целей, таких как:

- обеспечение социальной защиты уязвимых слоев населения по причине их неспособности самостоятельно решать социальные проблемы;

- обеспечение достойной пенсии и уровня жизни для пенсионеров;

- доступность образования и здравоохранения для всех категорий граждан;

- повышение МРОТ;

- введение прогрессивной шкалы налогообложения для НДФЛ;

- доступность жилья (социальное жилье, сертификаты), низкие ставки по ипотеке (1-2 \%, а не $10 \%$ в год).

Резюмируя все вышесказанное, акцентируем внимание на том, что социальная политика в России должна быть направлена на улучшение благосостояния ее граждан и достижение социальной стабильности. По нашему мнению, современную государственную социальную политику можно представить как баланс сил, степень согласия по текущим и перспективным социальным решениям, программам социального устройства и переустройства.

\section{Ссылки и примечания:}

1. Конституция Российской Федерации : принята всенар. голосованием 12 дек. 1993 г. 
2. Бондарев В.Г., Газимагомедов Г.Г., Стребков А.И. От социальной политики к конфликту, от конфоликта к социальной политике // Конфоликтология. 2015. Т. 2. С. 76-89.

3. Корнаи Я. Дефицит : пер. с венг. М., 1900. 608 с.

4. Черногор И.А. Проблема голода и недоедания в современном мире и России // Актуальные проблемы государства и общества в области обеспечения прав и свобод человека и гражданина. 2017. № 2-2. С. 205-211.

5. Социальное положение и уровень жизни населения России. 2017 : стат. сб. / Росстат. М., 2017. 332 с.

6. Таблица 1 составлена по данным Федеральной службы государственной статистики (http://www.gks.ru/).

7. С 1 мая MPOT впервые в истории сравнялся с прожиточным минимумом [Электронный ресурс] // Bectu.RU. 2018. 1 мая. URL: https://www.vesti.ru/doc.html?id=3012942 (дата обращения: 14.06.2018).

8. По данным официальных сайтов Организации Объединенных Наций (www.un.org) и Федеральной службы государственной статистики (http://www.gks.ru/).

9. Об утверждении государственной программы Российской Федерации «Обеспечение доступным и комфортным жильем и коммунальными услугами граждан Российской Федерации» : утв. постановлением Правительства РФ от 30 дек. 2017 г. № 1710.

10. Таблица 2 составлена автором по данным Росстата.

11. Рисунок 1 составлен по данным Росстата.

12. Шадрина Н.М. Проблема трудоустройства выпускников вузов // Молодой ученый. 2016. № 23. С. 368-372.

13. Об улучшении использования молодых специалистов : постановление ЦИК СССР, СНК СССР от 15 сент. 1933 г. // СЗ СССР. 1933. № 59. Ст. 356. Утратил силу в связи с изданием Постановления Совмина СССР от 29 мая 1948 г. № 1840.

14. По данным официального сайта Организации Объединенных Наций (www.un.org) и сайта «О пенсии». См.: Пенсии в разных странах мира 2016 [Электронный ресурс] // О пенсии. URL: http://55-60.ru/pensija/pensii-v-raznyh-stranahmira-2016-tablica.html (дата обращения: 14.06.2018).

15. Пенсии в разных странах мира 2016 [Электронный ресурс] // О пенсии. URL: http://55-60.ru/pensija/pensii-v-raznyhstranah-mira-2016-tablica.html (дата обращения: 14.06.2018).

16. Там же.

17. Class, Codes and Control. Vol. 1: Theoretical Studies towards a Sociology of Language / ed. by B. Bernstein. L. ; Boston, 1971. P. 85.

18. Donabedian A. The Criteria and Standards of Quality. Ann Arbor, 1982. 504 p.

19. Концепция Федеральной целевой программы развития образования на 2011-2015 годы : утв. распоряжением Правительства РФ от 7 февр. 2011 г. № 163-р.

\section{References:}

Bernstein, B (ed.) 1971, Class, Codes and Control, Vol. 1: Theoretical Studies towards a Sociology of Language, London, Boston, p. 85.

Bondarev, VG, Gazimagomedov, GG \& Strebkov, Al 2015, 'From social policy to conflict, from conflict to social policy', Konfliktologiya, Vol. 2, pp. 76-89, (in Russian).

Chernogor, IA 2017, 'The problem of hunger and malnutrition in the modern world and Russia', Aktual'nyye problemy gosudarstva i obshchestva $v$ oblasti obespecheniya prav $i$ svobod cheloveka i grazhdanina, No. 2-2, pp. 205-211, (in Russian).

Donabedian, A 1982, The Criteria and Standards of Quality, Ann Arbor, 504 p.

Kornai, J 1900, Deficiency, Moscow, 608 p., (in Russian).

Shadrina, NM 2016, 'The problem of university graduate employment', of graduates of universities', Molodoy uchenyy,

No. 23, pp. 368-372, (in Russian).

Social status and living standards of the Russian population: a statistical digest 2017, Rosstat, Moscow, 332 p., (in Russian). 